\title{
UM EXEMPLO DE ANÁLISE E DE ARGUMENTAÇĀO EM SINTAXE
}

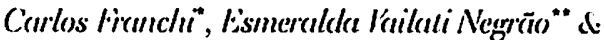 \\ Ana Licict N fïller.**
}

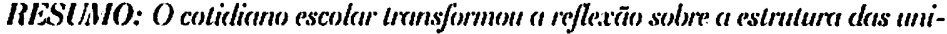
dades lingüisslicas em uma tarefa merrmente clessifficatória que parte de categoriass

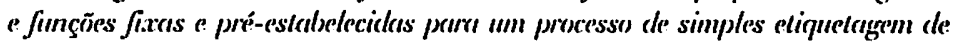

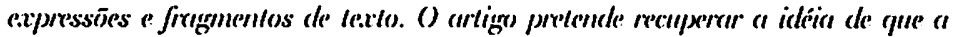

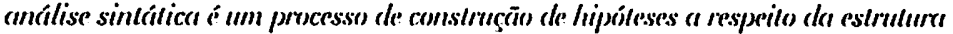

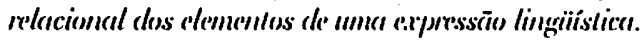

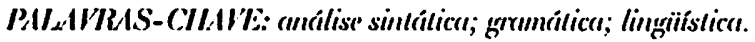

\section{INTRODUÇÃO}

c um modo geral, no cotidiano cscolar; o olhar para a língua
de modo a refletir sobre sua estruturação, transformou-sc cm uma tarcfa meramente classificatória. Darlas umas tantas categorias, (como nonec, verbo, artigo, oração, oração subordinada adjetiva ...) e umas tantas funções (sujeito, objeto direto, predicativo, oração principal), definidas de um modo ou de outro, as questõcs propostas aos alumos procuram quase scmpre levá-los a ctiquetar; com essas noçōes, algumas cxpressõcs e fragmentos de texto. Não pretendemos dizer que todo esse sistema nocional da análise tradicional deva ser apagado. Ao contrário, cle reflete intuiçōes interessantes c subsistentes em quase todos os modelos lingüísticos contemporâncos, sobre a cstrutura da língua. Mas o csvaziamento do trabalho de análisc, como um excrécio de mero reconhecimento, acabou por desenvolver no

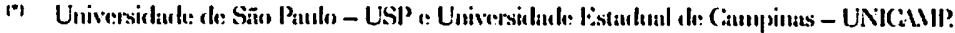

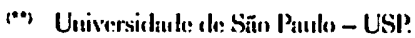

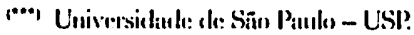


FRINC:III, Cartos el alii. Um exemplo de análise e de argumentăgão em sintaxe.

professor c no aluno a crença cm catcgorias c funçōes sintáticas já cstabclccidas, $\mathrm{cm}$ relação às quais as análiscs individuais cstarão ccrtas ou crradas, na medida cm que delas sc aproximam ou sc distanciam.

Assim, perdeu-sc o sentido de que, cada vez que atribuímos uma unidade lingiiística a uma catcgoria ou a associamos a uma determinada função sintática, cstamos construindo uma hipótese a respcito da cstrutura relacional da expressão intcira. Lissa hipótese deve bascar-se $\mathrm{cm}$ fatos da língua considerada, dirctamente obscrvávcis na cxpressão analisada ou cm outras cxpressõcs corrclacionadas. L são csscs fatos (c não a digressão sobre "definições") que devem funcionar como argumentos de suporte à hipótese levantada.

Esstc artigo pretende recupcrar o processo de análise dos fatos lingüísticos c, de certo modo, recupcrar as intuiçōes subjacentes à análisc tradicional. Vamos limitar-nos a uma oração bem simples do português c a uma análisc bem conhecida, como exemplo desse processo.

\section{ESTUDO DE UM CASO}

Considerc, de início, a oração:

(I) Os alunos acharam o caminho fácil.

Podemos dizer que essa oração é ambígua: duas interpretações diferentes podem ser a cla atribuídas. Pcrcebcram? Se não, cxperimentem colocá-la cm duas cenas distintas:

CENA I - Interpretação I: No fim de um curso, os alunos organizaram um churrasco no sítio do professor 'lom. Distribuiu-sc um mapa contendo instruções de como chegar ao local, por um ziguezague de estradinhas secundárias. As- 


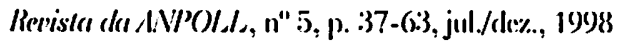

sim mesmo, apesar de o caminho ser difícil, seguindo o mapa, os alunos acharam o caminho fácil.

CENA II - Intcrpretação II: No parquc municipal, há dois diferentes trajetos para os que praticam caminhadas c conidas. Un deles, com três quilômetıos, é muito fácil de percorrer: plano, sem curvas c sombreado; o outro, ao contrário, com scis acidentados quilômetros, é difícil e destinado aos que têm mais fôlcgo e boas pernas. O primeiro é marcado com faixas amarclas cm troncos c pedias; o segundo, com marcas vermelhas. I Logo que chegaram, procurando pela cor das faixas, os alunos acharam o caminho lácil que deviam percorrer: aquele quc cra marcado pclas faixas amarclas.

Na cena I, "fácil" ć cntendido como a opinião ou avaliação do caminho pelos alunos c (1) corresponde a qualquer coisa como:

(2) a-Os alunos consideraram o caminho fácil, $b-\Lambda$ opinião dos alunos sobre o caminho foi que ele era fácil.

Na cena II, "fácil" especifica o caminho que foi encontrado pelos alunos, cm oposição ao caminho difícil c (1) pode scr parafiascada por:

(3) Os alunos encontraram o caminho fácil.

O leitor atento logo perccberá que, mesmo inscridas nesses cenários, resta ainda uma outra ambigüidade. De fato, a gente poderia cstar querendo dizer que foi fácil, para os alumos, encontrar o caminho:

Interpretação III:

(4) a-Os alunos acharam facilmente o caminho

b - Os alunos encontraram facilmente o caminho. 
FRWCIII, Cartos el alii. Um exemplo de análise e de argumentugü̈u em sintaxe.

$$
\text { *** }
$$

A qucstão que sc coloca ć: Por que uma oração que parece exatamente a mesma possibilita essas três interpretações? Duas respostas bem simples já devem estar na ponta da língua:

A - a gentc usou a oração (1) cm "contextos" difercntes (os dois "ccnários" acima) c é o contexto que leva a interpretar cssa oração de um modo ou de outro.

B - na verdade, tcmos dois verbos "achar" que são homófonos ou homônimos: o primciro "achar" é sinônimo de "considerar"; o segundo, ć sinônimo de "encontrar"; do mesmo modo, há dois itens lexicais diferentes na palavra "fácil": fácil 1 - adjetivo, c fácil.2 - advérbio.

Emm outros termos, a tripla ambigüidade de (1) não tcria nada a ver com os aspectos sintáticos, estruturais, da oração mas se resolveria cxclusivamente cm termos discursivos ou pragmáticos ou com recurso a uma diferença lexical, dicionarizável.

lissas duas respostas têm algo de verdadeiro, mas são respostas parciais. A resposta A é parcial porque cada contexto é único e diferente dos muitos contextos possíveis para o emprego de uma cxpressão. Li cada ocorrência de uma expressāo, no scu contexto, é também um acontecimento singular: A especificidade de cada contexto lingüístico c extra-linguiístico de uma cxpressão cm uso c os efcitos de cada ocorrência dessa expressão são extremamente relevantes para a análise do discurso, que envolve as condiçōes de uso c de produção. Mas, uma teoria gramatical visa a descrever os aspectos gencralizáveis, c não individuais, da construçāo das cxpressōes: a estabelecer princípios c reg"as que valham para todas as ocorrências de uma oração (para uma oração-tipo) c não para sua interpretação cm un 
cvento discursivo particular: Ora, como ć quc uma tcoria gramatical separaria, para a formulação desses princípios gcrais, no cstudo de (1), as infinitas situações possívcis, de um lado "os contextos da interpretaçāo I", de outro lado, "os contextos da interpretação II" c, finalmente os da interpretação III?

Assim, cmbora o recurso a contextos particulares de uso de uma oração c a cenários construídos para contcxtualizá-la artificialmente nos ajude a perceber a ambigüidade de uma oração $\mathrm{cm}$ situações específicas c singulares, não temos como nos refcrir aos inumcrávcis contcxtos possívcis (ou a classes de contextos) para cstabelecer gencralizações descritivas c princípios gramaticais sobrc a cstrutura c a forma das orações.

No caso da resposta $B$, tudo parece reduzido a uma questão de difcrenças no léxico. Mas verifica-se facilmente que o mesmo tipo de ambigüiidade aparece $\mathrm{cm}$ oraçõcs com verbos de que não poderíamos falar com propricdade cm "dois diferentes itens lexicais". O que dizer; por exemplo, da oração:

(5) Ojuiz julgou o seu amigo inocente?

Uma primeira interpretação é óbvia. Suponha que (5) tenha sido enunciada em uma situação como:

CENA III - Intcrpretação I: No juizado da comarca, depois de ouvir meu amigo $\mathrm{c}$ todas as testemunhas arroladas, bem como as demais provas constantes dos autos do processo, o juiz proferiu sua sentença. Afinal, meu amigo foi absolvido ou não? De um repórter, que saía da sala, ouvi, satisfcito que o juiz julgou seu amigo inocente.

Nessc caso, sua significação ć muito scmelhantc à que cstá cm (2), para o verbo "achar": 


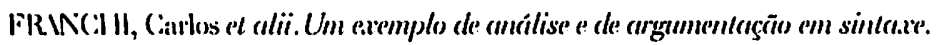

(6) a-O juiz considerou que o réu era inocente, $b-\Lambda$ opinião do juiz, sobre o réu, foi que ele era inocente

Mas a oração (5) podcria também significar outra coisa c isso pode ser visto $\mathrm{cm}$ um cenário mais complicado:

CENA IV - Interpretação II: Como jornalista, cu acompanhava um caso de homicídio; cu mesmo, encontrei tantas provas favorávcis ao suspcito, um homem simples, que me convenci de sua inocência c até me tornci scu amigo. No dia do julgamento, infelizmente, por problemas no trânsito de São Paulo, cheguci atrasado ao Fórum, onde um outro indivíduo cstava diante do juiz. O meirinho, que me conhecia e conhecia a amizade por aquele réu, já me foi adiantando: "Chegou tarde. 0 juiz (já) julgou seu amigo inocente. lì o pior é que o julgou culpado!"

Nesse cenário, já não podemos dizcr que (5) manifesta a opinião do juiz (para cfucm o réu cra culpado). "Inocente", cm "scu amigo inocente", somente especifica ou caractcriza o réu, cm relação a outros, como no caso de "fácil" em (3).

No caso de (1), podíamos atribuir a ambiguiidade geradora das diferentes interpretaçōes aos dois significados da palavra "achar" (encontrar; considerar). Já no caso de (5), não temos essa saída: não há razões para dizer que "julgar", nos dois cenários propostos, corresponde a dois diferentes itens lexicais.

İ̀m relação a tratar "fácil" como correspondendo a dois itens lexicais (fácil: adjetivo c fácil: advérbio), como poderíamos decidir cntre essa hipótese (para carla emprego um diferente item lexical) c a de que se trata do mesmo item com dois diferentes usos gramaticais, neutralizando-se a distinção cntre adjetivo c advérbio, como muitos sugerem? 
Em qualquer caso, o gramático tem sempre cpuc examinar sc, como consequiência da diferença lexical ou independentemente dela, a ambigiiidade não cstá associada a distintas cstruturas sintáticas, ou scja, aos modos de relacionar os elementos entre si c de construir com cles as unidades complexas que compõem a oração.

Assim, cstá na hora de cxaminar essa alternativa para explicar a ambigüidade da oração (1) de um modo mais geral. A hipótesc que vamos fazcr ć a de que, por detrás dessa oração superficialmente única - "os alunos acharam o caminho fácil" - existcm trĉs modos de construção, cada qual derivado de distintas relaçōes entre os scus constituintes. İm outros termos, devemos investigar sc essa oração reflete diferentes estruturas sintáticas. De um modo mais específico, podemos supor que a rclação estabelecida, no predicado, entrc os clementos "achar", "o caminho" c "fácil" ć uma quando leva à interpretação $I$, outra, quando leva à intcrpretação II c outra ainda quando lcva à interpretação III.

\section{A ANÁLISE TRADICIONAL DESSE CASO}

Como vocês sabem, a gramática tradicional faz a descrição da cstrutura sintática das oraçōes por meio de um conjunto de categorias morfológicas (nomc, verbo, adjctivo, ctc.), que recebem, nas orações, diferentes funçōcs sintáticas (sujcito, objeto dircto, predicativo, adjunto adnominal, adjunto adverbial, ctc.) que sc associam a cada termo ou sintagma da oração.

Ora, a oração (1) - "os alunos acharam o caminho fácil" - scria associada a três análises difcrentes, conforme a interpretação que fazcmos delas. Na interpretação II, a gramática tradicional analisa o adjetivo "fácil" na função sintática de adjunto adnominal de "caminho", formando com cle o objeto dircto nominal: "o caminho fácil"; na interpretação I, o adjetivo "fácil" scria analisado na função sintática de predicativo do 


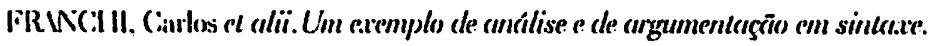

objeto direto, sem formar, com cste, um único constituinte. Na interpretação III, "fácil" pertenceria à classe dos advérbios e se analisaria como adjunto adverbial de modo, modificando "achar".

Vamos recordar o que a gramática tradicional quer significar com essas categorias c funçōes.

2.1. Comecemos pelas distinçōes entrc adjetivo c advérbio c, correspondentemente, entre adjunto adnominal $\mathrm{c}$ adjunto adverbial. De um modo gcral, a gramática tradicional utiliza critérios morfológicos c relacionais ou funcionais para distinguir adjctivo de advérbio.

$\mathrm{O}$ adjetivo ć uma palavra variável $\mathrm{cm}$ gênero $\mathrm{c}$ número (critério morfológico) que se relaciona a nomes substantivos ou modifica os nomes substantivos com que concorda (critćrio relacional). Um dos papćis do adjetivo é formar um substantivo complexo, na função de adjunto adnominal. Um adjunto adnominal ć uma palavra, locução ou mesmo oração (as oraçōes adjetivas) que "especifica ou delimita o significado de um nome substantivo, qualquer que scja a função deste", formando com cle um outro nome, ou um sintagma nominal complexo.

Para cxcmplificar; tomemos uma oração formadla por dois constituintes simples (scparados por colchctes para tornar as coisas mais claris) um nome, como sujcito e um verbo, como predicado:

\section{(7) / Mesa // quebra /.}

A gente pode "expandir" o nome-sujcito "mesa", acrescentando-lhe diferentes especificaçōes c formando nomes cada vez mais complexos, na posição de sujcito:

$$
\begin{aligned}
& \text { (8) } a-/ \text { Mesa // quebra /, } \\
& \text { b-/A mesa / /quebra / }
\end{aligned}
$$




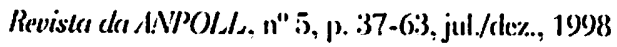

$$
\begin{aligned}
& \text { c- / A / mesa vermelha / / quebra /, } \\
& \text { d-/A / / mesa vermelha / da sala de reuniöes / / quebra /, }
\end{aligned}
$$

c assim por diante.

Nessa análisc, o adjunto adnominal não possui uma função independente, fora do sintagma nominal. Desse modo, dizce que "fácil" $\mathrm{cm}(1)$, na interpretação II, ć um adjunto adnominal, significa dizce que "fácil" modifica "caminho" c forma com cle um único constituinte - o nome-objeto dircto:

(9) $a-$ / os alunos / / acharam / o quê / /?,

$b-$ / os alunos // acharam / o / caminho fácil / / ,

c- / os alunos // acharam / o / caminho / que era fácil / / / .

d-/ roi / o caminho fácil / / que os alunos acharam /

No caso da interpretação III, porćm, a análise tradicional diz que "fácil" ć um advérbio na função, pois, de adjunto advérbial. É um advérbio, porque ć uma palavra invariável (critćrio morfológico) que modifica um verbo com que se relaciona (critério relacional). Nesse sentido, "fácil" não depende mais de "caminho" nem forma com ele um constituinte nominal; depende do verbo "achar" ou do sintagma verbal "achar o caminho" e com este se compōc. Ėm vez das paráliases de (9), teríamos as de:

(10) a-/ Os alunos / / acharam o caminho / como /?,

$b$ - / os alunos // / acharam o caminho / fácilffacilmente /,

c-/ os alunos / / / acharam fácilffacilmente / o caminho /,

d- / roifácil / / / os alunos / / acharem o caminho/ /,

e- / roi fácil/facilmente // que os alumos acharam o caminho /

O contrastc entre cssas duas interpretaçõos (II c III acima) fica mais visível se usarmos o critério morfológico das definições tradicionais de adje- 
FRWCIII, Cârlos el alii. Um exemplo de annálise e de argamentaçāo em sinkaxe.

tivo c advérbio. Isto é, se em vez de "o caminho" usarmos a forma plural "os caminhos" veremos que na interpretação II, o adjetivo-adjunto adnominal "fácil" varia c concorda com o substantivo modificado:

(11) Os alunos acharam / os caminhos fáceis /;

ao contrário, na interpretação III, em que "fácil" sc analisa como advérbio-adjunto adverbial, este fica invariávcl, pois não depende do substantivo $\mathrm{c}$ não concorda com cle:

(12) a-Os alunos / / acharam fácil / os caminhos /, b-Os alunos / / acharam os caminhos / fácil(mente) /

2.2. Vcjamos agora a noçāo tradicional de predicativo do objeto direto, com que se analisa (1) na interpretação I ("os alunos acharam/ consideraram o caminho fácil").

A gramática tradicional distinguc um pequeno conjunto de verbos, entre cles os chamados "verbos judicativos" (como "julgar", "achar", "considcrar", ctc.) que formariam um predicado verbo-nominal, ou scja, um predicado misto que possui dojs núclcos significativos: um verbo $\mathrm{c}$ um predicativo, estc cxpressando uma avaliação ou opinião do sujcito do verbo a respcito do objeto direto.

Atrás dessas palavras cstão algumas idćias simples sobre a cstrutura da oração com predicativo do objeto direto. Ėla diz que, $\mathrm{cm}$ orações com csses verbos, como (1) c (5):

Os alumos acharram o craminho fácil,

O juiz julgou o seu cmigo inocente,

"fácil" c "inocentc", na interprctação I, não formam um sintagma nominal complexo com, respectivamente, "o caminho" c "o scu amigo"; isto é, "fácil" c "inocente" cxpressam, no predicado, a opinião do sujcito da oração ("os alunos" c "o juiz") sobrc o objeto direto, como se dissessem: 
Revista da ANPOLI, , n" 5, p. 37-6.3, jul./1l\%., 1998

(13) Na opiniāo dos alunos/do juiz (näo forçosamente na opiniäo de quem fala), o caminho é fácil/o seu amigo inocente;

ou cntão:

(14) a-Os alunos acharam / que o caminho era fácil /

b-O juiz julgou / que o seu amigo era inocente /

Nessa interpretação I, "fácil" é certamente um adjetivo (c não um advérbio), tanto que a concordância é obrigatoria, ao contrário de (12):

(15) a-Os alunos acharam os caminhos fáceis,

$b-O s$ alunos acharam fáceis os caminhos;

(16) $a-O$ juiz julgou os seus amigos inocentes, $b-O$ juiz julgou inocentes os seus amigos.

Do ponto de vista catcgorial, portanto, não há diferença na análise de "fácil" como adjetivo nas interpretaçōes I c ll: tanto os adjetivos-adjuntos adnominais, quanto os adjetivos-predicativos, sc relacionam de algum modo aos nomes substantivos-objetos dirctos. Mas a gramática tradicional reconhece que cssa relação é difcrente nos dois casos, tanto que determinam difcrentes funçōes gramaticais para $\mathrm{o}$ adjetivo-adjunto $\mathrm{c}$ para $\mathrm{o}$ adjetivopredicativo.

Um modo intuitivo de descrever essa diferença é o de dizer que, no caso do adjetivo-predicativo, este, cmbora se relacione com o nome substantivo, não forma com clc um único constituinte nominal: o nome substantivo "o caminho" $\mathrm{o}$ adjctivo "fácil", cmbora relacionados, correspondem entretanto a dois constituintes relativamente autônomos, ambos exigidos independentemente pelo sentido do verbo. Como se o verdadeiro complemento do verbo não fossc um nomc, mas uma espécic de oração reduzida: 
FRWCi II, Carkss el alii. Um exemplo de cunilise e de argumenturgüo em sintaxe.

(17) a-Os alunos / acharam / o quê /?

$b$-Os alunos / acharam / (que) o caminho (era) fácil /.

"Pácil", por isso, possui uma função sintática que deriva dessa relação com o nome ("o caminho"), mas, também, de sua rclação com o vcrbo ("achar"), com que forma o predicado verbo-nominal.

Vamos tentar representar essa análisc, mediante os colchetes. Um modo seria representar o complemento de "achar" como se fosse uma oração reduzida, com dois clementos "cssenciais" (como dizia a gramática tradicional) $\mathrm{c}$ interdependentes:

(18)/ os alunos / / acharam / / o caminho / / fácil / / /.

2.3 - Comparemos as três análises cstruturais propostas:

A - na interpretação I, "fácil" ć um predicativo do objeto "o caminho", ambos como constituintes autônomos, formando uma oração reduzida; esta é que é o objeto direto do verho "achar";

B - na interpretação II, "fácil" ć um adjunto adnominal de "caminho", dependente desse nome que o adjetivo modifica e formando com cle um novo nome substantivo que é o objeto dircto de "achar";

C - na interpretação III, "fácil" ć um adjunto adverbial, dependente do verbo (ou do sintagma verbal) que o advérbio modifica, sem qualquer relaçāo com o substantivo "o caminho".

De um modo esquer ático e usando os colchetes para indicar os constituintes construídos por cssas relaçōes, teríamos: 
Revistu du ANPOLL, n" 5, p. 37-63, jul./de\%,, 1998

Os alunos acharam o caminho fácil

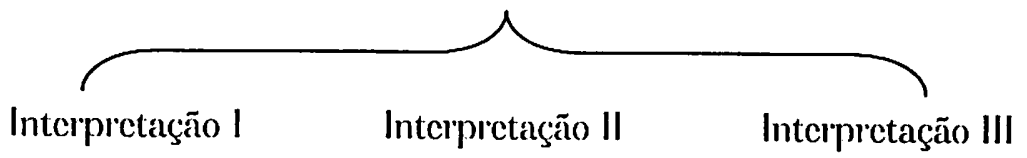

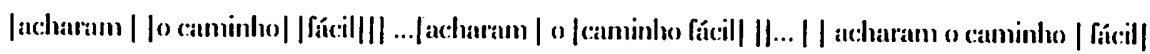

Dessc modo, as três interpretações apontam para três cstruturas sintáticas - determinadas pelas relações diferentes c pelas diferentes unidades complexas que clas compõcm, que a gramática expressava $\mathrm{cm}$ termos funcionais: "fácil" tcria três distintas funçōes sintáticas, conforme a interpretação de oraçōes como (I), respectivamente predicativa do objeto, adjunto adnominal c adjunto adverbial.

\section{BUSCANDO ARGUMENTOS SINTÁTICOS EM FAVOR DESSA ANÁLISE}

Diferenças estruturais, como essas, devem estar correlacionadas a outras propricdades sintáticas. Por exemplo, já vimos que a análise de "fácil" como adjetivo (nas interpretaçốcs I c II) cstá correlacionada a fatos de concordância, ao contrário da análise de "fácil" como advérbio (na interpretação III). Vimos, ainda, çuc carla uma dessas interpretaçōes levam a conjuntos distintos de paráfrases.

Vamos tentar mostrar, daqui para a frente, que a análisc tradicional está intuitivamente correta, fazendo aparecerem essas outras propricdades. Concentrar-nos-cmos somente sobre as interpretaçōes I c ll c sobre as funções sintáticas de predicativo c de adjunto adnominal, por razões de brevidade.

Um dos aspectos que distingue essas funções é o de que, $\mathrm{em}$ uma oração com objeto dircto c predicativo dessc objcto (na análisc tradicional), estes dois constituintes são relativamentc autônomos. Por isso, prefc- 


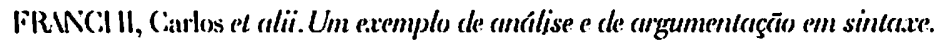

rimos tratá-los como formando uma espécic de oração reduzida, que cxpressa a opinião do sujcito a respeito do clemento analisado como objeto pcla tradição gramatical:

(20)Os alunos acharam / / o caminho / / fácil / /

lque o caminho era fácil /.

A oração reduzida "o caminho fácil", bem como a conjuncional "que o caminho cra fácil" expressam aquilo que os alunos pensam ou acham do caminho e aparecen como subordinadas completivas - complemento de "achar" - ou subordinada substantiva objetiva direta desse verbo.

Ao contrário, o adjunto corresponde a uma classc adjetiva dc cxpressõcs (palavias, locuçõcs, oraçõcs) que formam um nome complexo pcla modificação de um outro nomc. Assim, sc cxpressarmos a relação entrc o objeto direto e scu adjunto em uma oração plena, em vez de uma oração subordinada complctiva, vải aparccel uma subordinada adjuntiva ou subordinada adjetiva (rclativa):

(21) Os alunos acharam / o / caminho fácil / / / o / caminho / que era fácil / /.

Facilmentc vocês vcrificarão que (20) pode somente recebcr a interpretação I c (21), somente a interpretação II:

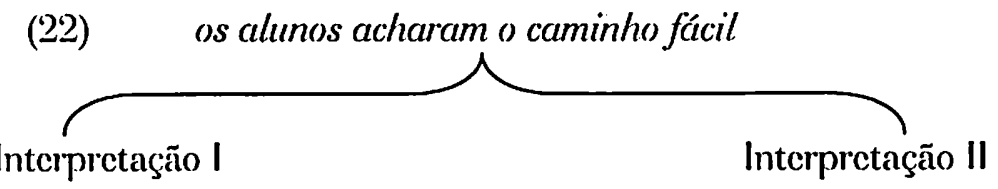

Os alunos acharam | |o caminho| | fácil| | os alunos acharan |que o caminho era fácil| os alunos consideraram fácil o caminlon os alunos acharam | o |caminho fácil| | os alunos acharam o | caminlıo |que era lácil|| os alunos cencontraram o caninho rácil 


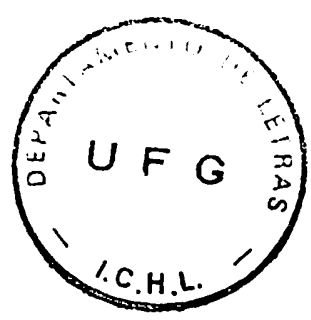

Com base nesse exemplo, observe que argumentar $\mathrm{cm}$ favor da hipótese estrutural que atribui a (1) e a todas as oraçōes semelhantes como (5), para cada interpretação uma diferente análise sintática, ou scja, dois modos de organização dos segmentos que compõem a oração, significa cncontrar fatos lingüísticos que, por sua especificidade, revelem a natureza das relações entre os constituintes.

A estratégia de argumentação é simples: procuramos encontrar fátos lingiiísticos que permitam contrapor as cluas estruturas, na medida $\mathrm{cm}$ que somente se correlacionam com uma delas e não com a outra. Com isso as propriedades sintáticas distintivas das estruturas consideradas vão aparecendo.

Uma técnica, cntrc outras, consiste $\mathrm{cm}$ opcrar sobrc as orações que supomos cxemplificar a cstrutura considerada, altcrando-a $\mathrm{cm}$ alguns aspectos mínimos. Comecemos por alteraçöes na ordem dos constituintes das oraçốcs (1) c (5). Por cxemplo:

(23) $a-($ s alunos acharam fácil o caminho, b- Ojuizjulgou inocente o seu amigo.

Imediatamente percebemos cue as duas orações de (23) já não são ambíguas. A clas corresponde somente a interpretação I, ou scja, aquela que supõc uma análise de "fácil" c "inocente" como predicativo, cxpressando, respectivamentc, a opinião dos alunos c do juiz sobrc o caminho c o scu amigo. lisaminemos, agora, uma outra ordenação:

(24)

$$
\begin{aligned}
& a-O s \text { alumos acharam of fácil caminho, } \\
& b-O \text { juiz julgou o seu inocente amigo. }
\end{aligned}
$$

Ocorre cxatamente o inverso. As orações de (24) também não são mais ambíguas, mas a clas corresponde somente a interpretação II que 


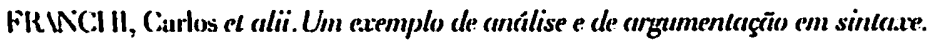

decorre de uma análise dos adjetivos rcordenados como adjuntos, internos ao próprio sintagma nominal. Como cxplicar o desaparecimento de uma das interpretaçōes pela simples alteração na ordem dos clementos?

No português, os adjctivos que intcgram um sintagma nominal, como adjuntos, normalmente scgucm o substantivo-núcleo dessc sintagma, como cm:

(25) a-Os alunos procuravam / o / caminho fácil / /, b-Os alunos procuravam / aquele / caminho fácil/ /.

Escolhemos para esse cxemplo o verbo "procurar" porcfuc, com cle, "fácil" só pode ser analisado como adjunto adnominal, interno ao sintagma nominal formado pcla adjunção. Nesse caso, quando o adjetivo antecede o substantivo núclco, como $\mathrm{cm}(26)$, cle fica dentro das frontciras desse sintagma nominal quc, à escpucrda, é marcada pelos detcrminantes como o artigo "o" c o demonstrativo "aquele":

(26) $a-O s$ alunos procuravam / o / fácil caminho / /, b-Os alunos procuravam / aquele / fácil caminho / /.

Por isso, as orações cm (27), no sentido relcvante, não são oraçōes gramaticais do português (c as marcamos com um "** para indicar essc fato):

(27) $a-*$ Os alunos procuravam fácil / o / caminho/ /, b- * Os alunos procuravam fácil / aquele / caminho / /.

Essa posição do adjctivo, relativamente independente e fora do sintagma nominal, somentc é possível quando também ć possível interpretar esse adjctivo como um predicativo. Isto é: a rcalização de "fácil" c "inocente" à csquerda do determinante, como $\mathrm{cm}(23)$ c (27), obriga à análise desses adjetivos como um constituinte independente do sintagma nominal, característica dos predicativos. Por isso, em (23), a mudauça na 
ordem climinou a possibilidade da interpretação II (c tornou tão cstranhas as orações de (27)).

Ao contrário, se construímos o sintagma nominal de modo a "prender" os adjetivos no interior de suas fronteiras (entre o determinante e o substantivo núcleo), somos levarlos a analisar esses adjetivos como adjuntos, integrantes do sintagma nominal, climinando a possibilidarle da interpretação $I$.

Podemos, assim, dizer que a interpretação I se associa a uma análisc cm que "fácil" c "o caminho" ("inocente" c "o seu amigo") são dois constituintes independentes (o adjetivo, como predicativo). L que a interpretação II depende de uma análise desses adjetivos como integrando um único constituinte com os substantivos que modificam:

(28) Os alunos acharam o caminho dificil

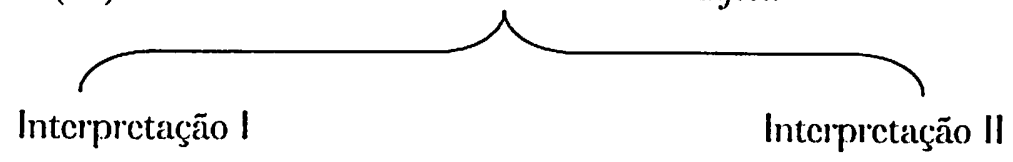

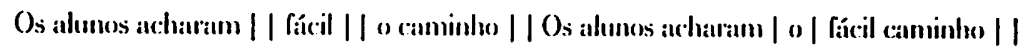
Os alunos consideraram o caminho fúcil Os alunos encontraram o caminho fícil

Vejam que a gente poderia criar uma "frontcira" à dircita do sintagma nominal. Suponha, por cxemplo, que "o caminho" cstivesse modificado por um outro adjunto, um sintagma preposicionado "do parque municipal que fica na reserva florestal". Vocês mesmos poderão verificar que no caso de:

(29) Os alunos acharam / o / caminho fácil / / do parque municipal que fica na reserva florestal / / /,

somente se pode analisar "fácil" como adjunto, integrando o sintagma. nominal. "Acharam" significa somente "encontrar". A análise c interpretação ć outra $\mathrm{cm}$ : 


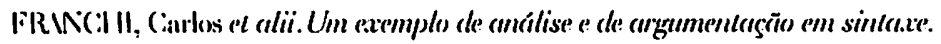

(30) a-Os alunos acharam o caminho do parque municipal que fica na reserva florestal fácil,

b-Os alunos acharam fácil o caminho do parque municipal que fica na reserva florestal

Nessas oraçōes, "fácil" se desloca para uma posição cxterna às frontciras do sintagma nominal (à esquerda, o detcrminante; à dircita, o longo adjunto preposicionado), forçando a interpretação do adjetivo como independente do substantivo-núclco, ou scja, como predicativo:

(31) Os alunos acharam que o caminho do parque municipal que fica na reserva florestal era fácil.

\section{EXPLORANDO UMA IDÉEIA DA ARGUMENTAÇĀO PRECEDENTE}

A alteração na ordem dos constituintes de (1) e (5) funcionou como uma estratégia para evidenciar dois diferentes modos de hicrarquização desses constituintes. A hipótesc auxiliar de que nos servimos foi:

- a de que nome + adjunto adnominal forma um único constituinte nominal uma das interpretações da oração (1); nesse caso, o adjetivo não pode ocupar posições fora do sintagma nominal;

- a de que nome + predicativo forma uma oração reduzida, com dois constituintes (nome c adjctivo) relativamente autônomos, autonomia que se mostra em uma maior liberdade de movimento do adjetivo, levando a outra interpretação da oração (1).

4.1. Uma outra estratćgia permitirá reforçar nossa argumentação. Sabemos que, muitas vezes, em certas transformaçōes que podemos fazer de 


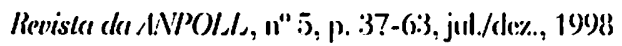

uma oração, mantendo basicamente a mesma significação um constituinte inteiro é movido de uma posição para outrat. Isso permite testar com maior precisão quais são os limites de um constituinte, bascando-nos no fato de que, quando se desloca um constituinte de uma posição para outra, todos os elementos de que é formarlo devem mover-se juntos.

Comecem por observar essa generalizaģão $\mathrm{cm}$ um exemplo mais simples, em cue se passa um adjunto adverbial de tempo de sua posição no fim da oração para a posição inicial:

(32) a-As coisas eslavam confusas maquela reunião dos condôminos,

b-Naquela reumião dos condôminos, as coisas estavam confissas,

c- * Naquela reumiāo, as coisas estavam confusas dos condôminos,

d-* Reumiāo dos condôminos, as coisas estavam confusas naquela.

Como se observa pela agramaticalidarle $\left(^{*}\right)$ de (32-c, dl), não se pode cindir o adjunto adverbial movido, deixando parte para trạ́s sem completa alteração do sentido.

Aggora, cxaminemos o caso das construçōes na voz passiva em que o sintagma nominal ocupando a posiçĩo de oljeto dircto, na voz ativa, passa a ocupar a posição de sujeito da oração. Que todo constituinte deve ser movido fica evidente se observarem que a gramaticalidade de $(33, \mathrm{~b})$ e a agramaticalidade das orações $(33, c, d)$ se lhe quiscrmos dar a mesma interpretação referencial de $(33, \mathbf{a})$ :

(33) $a-J o \tilde{a}$ o construiu / uma casa de campo branca /, b- Uma casa de campo branca foi construída por . Joũo, 


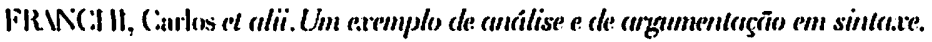

$$
\begin{aligned}
& c \text { - * Uma casa de campo foi construída branca por .João, } \\
& d-\text { * Uma casa branca foi construida de campo por João. }
\end{aligned}
$$

lintāo, se nossa análise de (1) c (5) cstá correta, espera-se que clas possam ser correlacionadas a duas construções passivas, uma delas correspondendo à primcira interpretaģão c outra, à segunda interpretação. Vamos justificar isto.

- Se "fácil" (ou "inocente") é um constituinte autônomo, independente do objeto direto, quando se analisa como predicativo, somente o sintagma nominal "o caminho" (ou "o scu amigo") ocupará a posição de sujeito na passiva correspondente. 'De fato, teremos:

(34) a - O caminho foi achado fácil pelos alunos, b-O seu amigo foi julgado inocente pelo juiz.

- Se "fácil" (ou "inocente") integra o objeto direto, como adjunto, todo o sintagma nominal, incluído o adjetivo, deve mover-sc para a posisã̃o de sujeito. Basta testar; para ver que isso, de fato, ocorre.

(35) a - O caminho fácil foi achado pelos alunos, b-O seu amigo inocente foi julgado pelo juiz.

Mas é preciso obscrvar que as construções de (34) possuem somente a interpretação I, em que "fácil" c "inocente" correspondem à avaliagũono que "os alumos" ou "o juiz" fazem do objeto direto. If que as passivas de (35) somente recebem a interpretação II.

Desse modo, as construçōes passivas reforçam a hipótese de que a ambigüidade geradora das duas interpretaçōes das oraçōes (1) e (5) é de natureza cstrutural: "caminho"/ "o scu amigo" " fácil"/ "inocente" se relacionam de dois diferentes modos e constituem dois diferentes tipos de constituintes, cmbora realizados na mesma sequiência sonora. 
Com as passivas, conseguimos um novo par distintivo de construções que corroboram nossa análise:

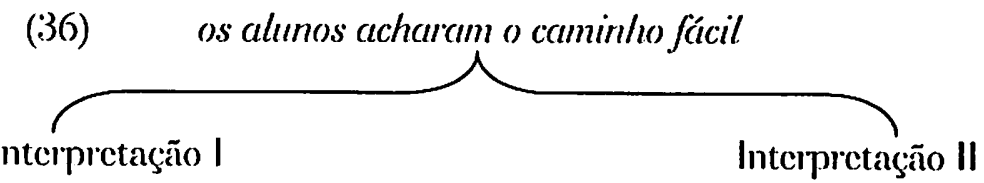
O caminho foi acthado fácil pelos alumos
O camindo fícil foi achado preless alunos
Os allunos considenaram fícil o caminlon
Os alumus concontranam o camninlo fícil

$$
* * *
$$

4.2. Além da passiva, outros deslocamentos de constituintes podem ser cxaminados. Consideraremos dois deles.

O primeiro, conhecido como "topicalização", consiste cm mover todo um constituinte para o início da sentença para destacá-lo entre os demais como "aquilo de que se fala" (como "tópico"). Vamos estudar melhor essats construçōes mais adiante, bastando agora alguns cxemplos:

(37) a - liu nāo vou ler nunca esse livro de crítica, b- Esse livro de crílica, cu não vou ler nunca;

(38) $a-\Lambda$ gente nunca imaginaria encontra; aqui, uma coisa tão estapafím dia e de mau gosto, b- Ima coisa tão estapafúrdia e de man gosto, a genle munca imaginaria encontrar aqui.

'làmbém podem deslocar-sc para a posição inicial os elementos que estão sob o foco de uma interrogação, isto é, quando sc questiona não 


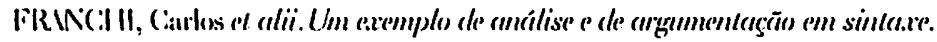

sobre se uma oração é verdadcira ou falsa, mas se questiona um dos constituintes ou parte da oração. Por exemplo:

(39) a - locê devolveu para a biblioteca que livross de lingüística, adtairidos no ano passado?

b-Que livros de lingüística, adquiridos no ano passado, você devolveu para a biblioteca?

Outra vez, como no caso da passiva, os processos de topicalização e de deslocamento dos constituintes interrogados para o início da oração somente scrão gramaticais quando o constituinte todo for moviclo. Vocês podem observar como ficam ruins as oraçōes cm que o processo incirle somente sobre parte do constituinte:

(40) a - * Esse livro, eu não vou ler nunca de crílica,

b- * Uma coisa tão estapafúrdia, a gente nunca imaginaria encontrar aqui e de mau gosto;

(41) * Que livros você devolveu para a biblioteca dle lingüirstica, adquividos no ano passado?

Podemos, agora, usar o mesmo raciocínio que fizemos no caso da passiva. A análise a favor da qual estamos argumentando supōe que, nas orações (1) e (5), na interpretação I, o adjetivo ("lácil" ou "inocente"), na função de predicativo, um constituinte independente do substantivo ("calminho" ou "o seu amigo"), não se desloque à escpuerda quando o sintagma nominal for topicalizado ou interrogado na posição inicial. De fato, obscrvem as oraçōes:

(42) a-Os alunos acharam o caminho do sítio fácil;

b-O caminho do sítio, os alunos acharam fácil,

c- * O caminho do sítio fácil os alunos acharam (no senticlo de "consideraram") 
Revista da ANP(OLL, n" 5, p. 37-63, jul./dl\%.., 1998

O próprio adjetivo pode topicalizar-se independentemente:

(43) Bem fácil, os alunos acharam o caminho do sítio, hem?

Agora, observem as oraçõos em que se desloca um constituinte interrogado, no caso da intcrpretação l:

(44) $a-O s$ alunos acharam que caminho fácil?

$b$ - Que caminho os alunos acharam fácil?

$c-O$ quê que os alunos acharam clo caminho?

Essas orações somente podem ser interpretadas com "achar" no scntido de "considcrar", "julgar". Sc quiscrmos construir oraçōes com o objcto dircto topicalizado ou interrogado na intcrpretação II ("achar" no scntido de "cncontrar"), aqucla cm que o adjetivo ("fácil") cstá na função de adjunto, fazcndo parte integrante do sintagma nominal $\mathrm{c}$ formando um único constituintc com o substantivo núclco ("caminho"), cntão todo o constituinte sc desloca para o início da oração. Em vez de (43), teremos:

$$
\begin{aligned}
& \text { (45) a-O caminho fácil, os alunos (o) acharam, } \\
& \text { b-O caminho fácil do sítio, os alunos (o) acharam, }
\end{aligned}
$$

c cm vez de (44):

(46) Que caminho fácil os alunos acharam?

(a que se poderia responder que cles cncontraram o caminho fácil marcado por faixas vermelhas nas pedras $\mathrm{c}$ nos troncos).

Um resumo dos achados nestes últimos parágrafos: 
FRUNCIII, Carlos et alii. Um exemplo de análise e de argumentaģōo em sintaxe.

(47) Os alunos acharam o caminho fácil

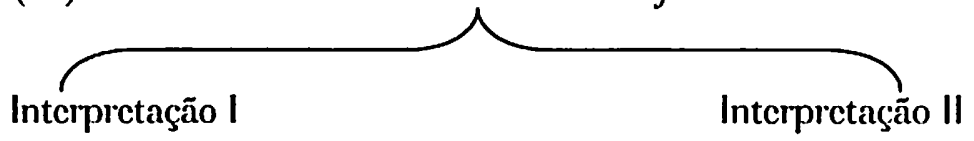

O caninlıo, os alunos (o) acharam fácil

Que caninho, os alunos acharanı fácil?

Os alunos consideraram fácil o canninho
O caninho fácil, os alunos (o) ac:haram

Que caninló fácil os alunos achauram?

Os alunos encontraram o caminlo fácil

$$
\star * *
$$

4.3. Aos fatos lingüísticos que acumulamos $\mathrm{cm}$ favor da hipótesc que cxplica a ambigüidade das oraçōes (1) c (5) como dependente de sua cstrutura sintática, valc a pena acrescentar mais um que, cmbora não cnvolva deslocamentos, bascia-sc no mesmo csquema argumentativo. Tìata-sc de fenômeno cnvolvendo a pronominalização. Isto porque os itens lexicais a que chamamos pronomes têm a propricdade de recuperar (do contexto lingüístico) todo o sintagma nominal, c não somente o substantivo ncle contido.

Observem o que ocorre nos cxemplos:

(48) As crianças barulhentas desta classe ouviram, com muita atenção a história de mistério que eu contava, a - Elas pareciam estar em outro mundo, enquanto a ouviam, b - * Elas barulhentas desta classe pareciam estar em outro mundo enquanto a de mistério que eu contava ouviam.

A oração (48,a), em quc os pronomes "clas" c "a" substituem todo o sintagma nominal (respectivamente, "as crianças barulhentas desta classc" c "a história de mistério que cu contava") ć uma oração comum do portuguĉs. Ao contrário, parcce muito mais que cstranha, na verdade 
agramatical, a oração $(48, b) \mathrm{cm}$ que o pronome substitui somente os substantivos-núcleo ("crianças" c "história"). Por isso ć que a pronominalização também pode cvidenciar os limites entre os constituintes de uma oração.

Suponham, cntão, que, na cena proposta como contexto para a intcrprctação I, o anfitriāo, professor 'lom, disscssc a um colega:

(49) Os alunos nāo custaram para encontrar o caminho. Eles o acharam fácil,

ou que cle tenha dito simplesmente $(50, a)$ c um colega tenha concordado $\operatorname{com}(50, \mathrm{~b})$ :

(50) $a-($ s alunos acharam o caminho fácil, $b-\hat{E}$, de fato. Pelo visto, eles o acharam fácil.

Nesses dois casos, sabemos que, na oração -"cles o acharam fácil" -, "o caminho" é um constituinte independente de "fácil", já que o pronome substitui somente "o caminho" (scm absorver também "fácil" c tanto (49), quanto $(50$, b)) são oraçõcs perfeitas. Mais ainda, cm (49) c cm $(50, \mathrm{~b})$, a ambiguiidlade da oração "os alunos acharam o caminho fácil" desaparcccu, sendo possível somente a interpretação I, com o adjetivo analisado como predicativo do objeto direto.

As coisas andam cm outra direção na cena ll. Se lizéssemos o dizerem:

(51) Os rapazes têm que encontrar o caminho mais fácil. - Fica tranquiilo que os rapazes já o acharam.

O pronome " $\mathrm{o}$ " substitui, agora, todo o sintagma "o caminho mais fácil", o que mostra que, ncssa intcrpretação II, quando "achar" significa "cncontrar", "o caminho" c "fácil", analisado como adjunto adnominal, formam um único constituinte. 


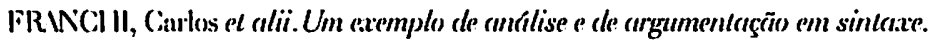

\section{UMA BREVE REVSĀO}

Uma pequena revisão de como procedemos neste artigo. Escolhemos uma oração com três interpretações bem claras nos contextos criados em diferentes cenários. Obscrvamos que tal ambigüidade poderia resultar do fato de aspectos lexicais c poderia resolver-sc $\mathrm{cm}$ contextos adequados. Mas obscrvamos também que a ambigüidade geradora das duas interpietações não fica bem explicada nesses planos lexical c discursivo: cla está vinculada a duas cstruturas sintáticas da expressão supcrficial:

- na interpretação I, vimos que "fácil" sc analisa como predicativo do objeto dircto, como constituinte independente $\mathrm{cm}$ relação ao objeto dircto "o caminho", com o qual formaria uma oração reduzida;

- na interpretação II, "fácil" sc analisou como adjunto adnominal, formando com "o caminho" um único constituintc: o sintagma nominalobjcto dircto de achar "o caminho fácil";

- na intcrprctação III, "fácil" sc comporta como advćrbio; não sc relaciona com "o caminho", mas com o verbo "achar" o o sintagma verbal "achar o caminho"

A claboração de uma gramática, entretanto, supõc mais do que a construção de hipóteses para um fato lingüístico isolado. Precisamos scmpre verificar cssas hipóteses, colocando-a sob avaliação cmpírica pelo exame de outros fatos linguísticos que possam ser explicados como decorrência da análise particular que fizcmos.

Assim, verificamos que a análisc proposta permitiu corrclacionar uma sćric de outros fatos linguísticos, $\mathrm{cm}$ outros domínios da gramática, o que permitc gencralizaçōes descritivas interessantes. Nesse sentido, cxaminamos (c utilizamos como critérios de análise $\mathrm{c}$ basc da argumentação): 
Revisha da INPOLL, n" 5, p. 37-033, jul./de\%, 1998

- difcrentes modos de cxpressar; por mcio de orações, a rclação entre o nome c o adjetivo;

- aspectos morfológicos (fatos de concordância) correlacionados a cssas diferentes rclações;

- condições distribucionais como as cstabelecidas sobrc a ordem das palavras ou as posições contcxtuais do constituinte cstudado;

- ccrtas correspondências entrc a cxpressão analisada c outras orações scmanticamentc aparentadas, como na formação das construções passivas, nas topicalizações c nas interrogativas c nos casos de pronominalização.

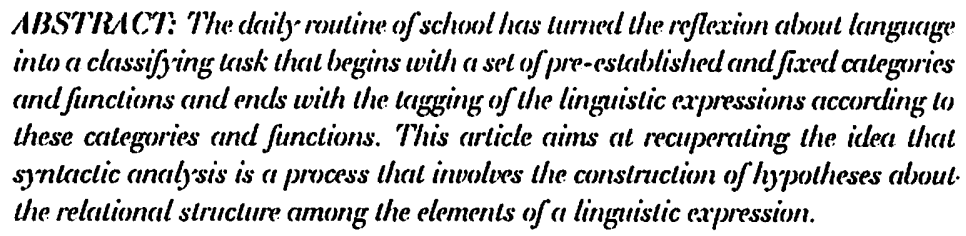

KIEIVORIDS: synloclic analysis; gorummar; linguistics. 